[DOI: 10.24214/jecet.A.10.4.54252]

Juurnal of Enviranmental Science, Computer Science and

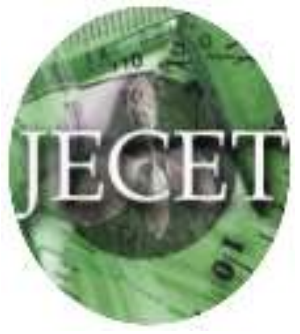
Engineering \& Technology

An International Peer Review E-3 Journal of Sciences and Technology

Available online at www.jecet.org

Section A: Environmental Science

Research Article

\title{
Alcoholic Green Fruits Extract of Abroma augustam Linn. (Ulatkambal) Used for the Treatment of Diabetes
}

\author{
M. Das, Aurpita shaha1 ${ }^{1}$ K.K. Biswas ${ }^{2}$ and *R. K. Shaha ${ }^{2}$ \\ ${ }^{1}$ Department of Pharmacy, Pabna University of Science and Technology, Rajarhat, \\ Pabna-6600. ${ }^{2}$ Department of Biochemistry and Molecular Biology, \\ Rajshahi University, Rajshahi-6205, Bangladesh.
}

Received: 14 August 2021; Revised: 03 October 2021; Accepted: 12 October 2021

\begin{abstract}
Herbal medicines are getting more importance in the treatment of various diseases like diabetes, cancer and hepatic disorder. Diabetes mellitus still is the serious medical problem to human health due to rapid increase and cause of death in the developed and developing countries. It characterizes by hyperglycemia because there is the defect in insulin secretion, or the reduced sensitivity of the tissue to insulin formation. Apart from currently available therapeutic options, many herbal medicines have been recommended for the treatment of diabetes. The newer anti-hyperglycemic drugs continue searching because the existing synthetic drugs have several limitations. Herbal drugs are prescribed widely because of their effectiveness, less side effects and relatively low cost. Abroma augustam Linn is one of such ayurvedic remedy (medicinal plant) that has mentioned in many Bangladesh and Indian medicinal literatures. Abroma augustam contains several kinds of glycosides, flavonoids, Gallic acid and phenolic compounds in varies plant parts extract. Researchers have shown the scientific support for the use of Abroma augustam roots, bark and leaves extract in the traditional system of medicine for the treatment of diabetes mellitus. However, there are no data available about the hypoglycemic activity of green fruits and mature flower of $A$. augustam. Therefore, the current study aims to investigate the antidiabetic potential of A. augustam green fruits and mature flowers extract for preparing new treatment of diabetes mellitus with the formulation of novel drugs.
\end{abstract}

Keywords: Herbal medicine, Ulatkambal, diabetes, Green fruits. 


\section{INTRODUCTION}

Medicinal plants play a leading role in the treatment of varieties of human diseases from the past of human development ${ }^{[1]}$. In Bangladesh and India, medicinal plants are widely used by all sections of population and over 6500 species of plants used by several ethnic communities ${ }^{[2]}$. The medicinal plants are useful for healing as well as for curing of human diseases because of the presence of bioactive phytochemical constituents [3]. Phytochemicals are primary and secondary compounds naturally occurring in the medicinal plants that have defense mechanism and protect from various diseases. Chlorophyll, proteins and common sugars are included in primary constituents and secondary compounds have terpenoid, alkaloids and phenolic compounds ${ }^{[4]}$.

Diabetes mellitus is one of the common endocrine disorders prevalent in almost all of the countries. This chronic pathology have characterized by hyperglycemia caused by defective insulin action, insulin secretion, or the combination of both. The number of people with diabetes is increasing due to population growth, ageing, urbanization and increasing prevalence of obesity and physical inactivity. This disease has a significant effect on social, psychological as well as physical quality of life ${ }^{[5]}$. Approximately 366 million people are suffering from Diabetic mellitus around the world and the incidence of this disease is predicted to be more than double by the year of $2030{ }^{[6]}$. The future trend indicates that more than $60 \%$ of the world's diabetic population will be in Asian countries because of the rapidly occurrence in socioeconomic and industrialization growths ${ }^{[7] .}$ Apart from currently available therapeutic options, many herbal medicines have recommended for the treatment of diabetes. Abroma augustam Linn (Family-Sterculiaceae or Malvaceae) commonly known as Ulatkambal in (Bangla/Hindi) and Devil's cotton in English is a special medicinal plant uses for curing various diseases by the Bangladeshi village traditional practitioner. Ulatkambal is a shrub or small tree about 2-3 meters in height. Leaves and seeds of A. augustam are considered to be edible in Bangladesh, India and New Guinea. The flowers are bisexual, deep red or yellowish with purple bases and the fruits (capsule) are observed pyramidal covered with irritating hairs and with five prominent angles or wings[Figure-1,2] $]^{[8,-10]}$.

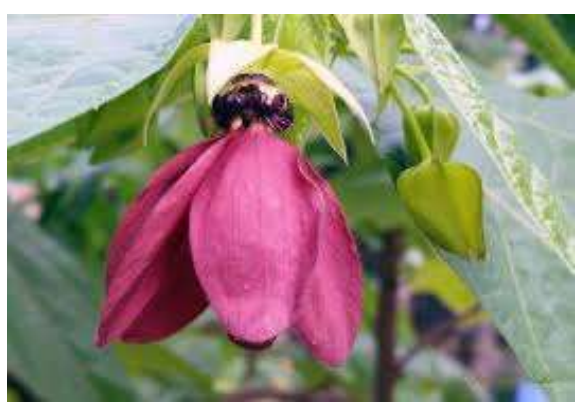

Fig. 1: A.Augusta (mature flower).

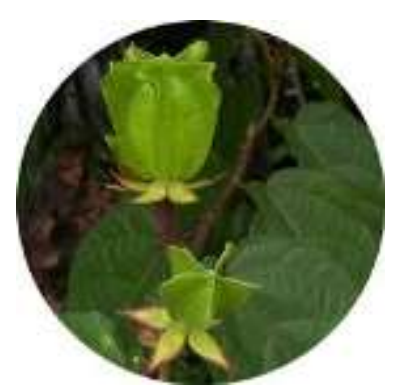

Fig.2: A. Augusta (Green Fruits).

Researchers have shown the scientific support for the use of Devil's cotton roots, bark and leaves extract in the traditional system of medicine for the treatment of type-2 diabetes and it has the inhibitory activity of glucose absorption in the gut ${ }^{[11]}$ as a result, it manages the high blood sugar ${ }^{[12]}$. However, there are no data available about the hypoglycemic activity of green fruits and flower extracts of A. augustam. Therefore, the current study aims to investigate the antidiabetic potential of A. augustam alcoholic extract of green fruits and mature flowers for preparing new treatment of diabetes mellitus. 


\section{MATERIAL AND METHODS}

\subsection{Collection of Plant Material:}

Green fruits and flowers of Abroma augustam L collected from the Rajshahi University campus area, Rajshahi, Bangladesh. The green fruit sand flowers dried under shade for 8 days with occasional sun drying. Lastly, these samples dried in a fixed temperature incubator $\left(40^{\circ} \mathrm{C}\right)$ for 3 days. The dried materials ground into fine powder using a mechanical grinder and stored at room temperature in polyethylene bags for further uses.

\subsection{Preparation of Extract}

2.2.1.For preparation of green fruits extract: $200 \mathrm{~g}$ of green fruits grinding dry powder were taken separately into two round 1L shaking flask and soaked with $500 \mathrm{ml}$ of Ethanol and 500ml Methanol for 2 hours. Then the mixture solutions separately shake at $200 \mathrm{rpm}$ for 24 hours by using shaking incubator (Electric shaker Model-HR, Bombay, India).

2.2.2.For preparation of mature flower extract: Similarly, 200gm of flower grinding powder were soaked with $500 \mathrm{ml}$ of ethanol and 500ml methanol in two conical flasks for 2 hours and shake at 200 rpm for 24 hours by using the same shaking incubator. Then, these four (4) extracts filterated separately by using a fine white cotton cloth followed by Whatman No.1 filter paper and concentrated to $90-100 \mathrm{ml}$ with a rotary evaporator separately. The concentrated ethanol \& methanol extracts of fruits and flower dissolved separately into $300 \mathrm{ml}$ Petroleum ether $\left(40-60^{\circ} \mathrm{C}\right)$ at room temperature for removal of fat and waxes. Finally, the fat free ethanol and methanol extracts of fruits and flowers dried by using freeze dryer and stored at $4^{\circ} \mathrm{C}$, into four-glass vial with airtight caps for further phytochemicals treatments.

2.2.3. Chemicals and Reagents: All chemicals and reagents used for this research works purchased from Sigma Co. (India) and were analytical grade. Gallic acid (GA), and $\mathrm{FeCl}_{3}$ were purchased from Sigma Chemical Co. (USA); Folin-Ciocalteu phenol reagent (FCR), and Hager's reagent was purchased from Biotech (Beijing, China).

\section{PHYTOCHEMICAL SCREENING}

The ethanol and methanol extract of A. augusta (Linn.) green fruits and flower powder were screened qualitatively for the presence of phytochemical constituents such as reducing sugars, tannins, alkaloids, steroids, glycosides, carbohydrates, saponins and flavonoids following the standard procedures $[13,14]$. The standard qualitative methods that were used $1 \%$ of the extract powders to perform the tests are as follows:

3.1. Test for alkaloids: $2 \mathrm{ml}$ extract solution and $0.2 \mathrm{ml}$ dilute HCL mixed together with $0.1 \mathrm{ml}$ of iodine solution (Wagner's reagent). Reddish brown precipitated obtained to confirm the presence of alkaloids. $2 \mathrm{ml}$ extract solution and $0.2 \mathrm{ml}$ diluted HCL mixed together with $0.1 \mathrm{ml}$ of picric acid (Hager's reagent). Yellowish precipitate observed which confirms the presence of alkaloids.

3.2. Test for Steroids: $10 \mathrm{mg}$ of extract dissolved in $1 \mathrm{ml}$ of chloroform. Then $1 \mathrm{ml}$ sulfuric acid added. It observed that chloroform layer acquired reddish brown color and acid layer showed green fluorescence thus confirming the presence of steroids.

3.3. Test for Terpenoids: $1 \mathrm{ml}$ of extract of each solvent and add $0.5 \mathrm{ml}$ of chloroform followed by a few drops of concentrated sulphuric acid, formation of reddish brown precipitate indicates the presence of terpenoids in the extract. 
3.4. Test for flavonoids: $10 \mathrm{ml}$ of the extract solution hydrolyzed with $10 \% \mathrm{H}_{2} \mathrm{SO}_{4}$ acid. This was extracted with ether and divided into 3 portions:

*To first potion, $1 \mathrm{ml}$ dilute sodium carbonate solution added and a pale yellow color seen which confirms the presence of flavonoids.

- To second portion, $1 \mathrm{ml}$ dilute sodium hydroxide solution added and yellow color observed, which means that flavonoid is present.

- To third portion, $1 \mathrm{ml}$ dilute ammonia solution added and greenish yellow color obtained that showed flavonoid is present.

3.5. Test for reducing sugars: To $5 \mathrm{ml}$ of extract solution, $5 \mathrm{ml}$ of (Fehling $\mathrm{A}+$ Fehling B) solutions added. The mixture boiled for 5 minutes in a water bath. A Brick red color precipitate observed thus confirming the presence of reducing sugars

3.6. Test for tannins: $5 \mathrm{ml}$ extract solution mixed with $1 \mathrm{ml}$ of $10 \%$ lead acetate solution. Yellow precipitate obtained, which confirms the presence of tannins. To $5 \mathrm{ml}$ extract solution, $1 \mathrm{ml}$ of $10 \%$ potassium dichromate solution added. No yellowish brown precipitate obtained which confirms the presence of tannins.

3.7. Test for Glycosides: To a small amount of extract, $1 \mathrm{ml}$ of water and few drops of Sodium hydroxide $(\mathrm{NaOH})$ solution added. Yellow color observed, which confirms the presence of glycosides.

3.8. Test for carbohydrate: $2 \mathrm{ml}$ of extract sample taken and $2 \mathrm{ml}$ conc. Sulfuric acid added to it. Reddish yellow ring confirms the presence of carbohydrate.

3.9. Test for Saponins (Foam Test): $1 \mathrm{ml}$ of extract solution diluted to $20 \mathrm{ml}$ with distilled water. Then it shaken for 15 minutes. No layer of foam was formed which suggest that saponins is absent.

3.10. Quantitatively Phytochemical analysis: The phenolic and flavonoid compound identified quantitatively using UV-spectrophotometer with standard marker compounds.

3.10.1. Determination of total phenol content: The total phenol content was determined according to Folin Ciocalteu's reagent method ${ }^{[15] .} 0.5 \mathrm{ml}$ of extract and $0.1 \mathrm{ml}(0.5 \mathrm{~N})$ Folin-Ciocalteu's reagent was mixed and the mixture was incubated at room temperature for $15 \mathrm{~min}$. Then $2.5 \mathrm{ml}$ saturated sodium carbonate solution was added and further incubated for $30 \mathrm{~min}$. at room temperature and the absorbance was measured at $760 \mathrm{~nm}$. Gallic acid was used as a positive control [16]. Total phenol values are expressed in terms of gallic acid equivalent ( $\mathrm{mg} \mathrm{g}^{-1}$ of extracted compound).

3.10.2. Determination of flavonoid content: The flavonoid content was determined according to aluminium chloride colorimetric method ${ }^{[17]}$. The reaction mixture consisting in a final volume of $3 \mathrm{ml}$, $1.0 \mathrm{ml}$ of sample $(1 \mathrm{mg} / \mathrm{ml}) 1.0 \mathrm{ml}$ methanol and $0.5 \mathrm{ml}$ of $(1.2 \%)$ aluminium chloride and $0.5 \mathrm{ml}(120$ $\mathrm{mM}$ ) potassium acetate was incubated at room temperature for $30 \mathrm{~min}$. The absorbance of all the samples was measured at $415 \mathrm{~nm}$. Quercetin was used as positive control ${ }^{[18,19]}$. Flavonoid content is expressed in terms of Quercetin equivalent (mg g -1 of extracted compound).

3.11. Animal Tests: Animal models comprised of 45 mature Swiss Albinomice (weight $30 \mathrm{~g} \pm 5 \mathrm{~g}$; age 2-3 months) collected from animal house of the Biochemistry Department, Rajshahi University. The micehoused in standard metal wire cages under standard lab conditions of $12 \mathrm{~h}$ light-dark cycle, temperature $\left(20^{\circ} \mathrm{C} \pm 2^{\circ} \mathrm{C}\right)$, relative humidity $(50 \pm 15 \%)$, and standard diet and distilled water supply. The animal experiments pursued combinedat the Department of Biochemistry and Institute of Biological science, Rajshahi University, Bangladesh. 
Ethical Approval: The current experimental procedure was approved by the Institutional Animal, Medical Ethics, Biosafety and Biosecurity Committee (IAMEBBC) for Experimentations on Animal, Human, Microbes and Living Natural Sources, Institute of Biological Sciences, University of Rajshahi, Bangladesh (Approval no.: 225/320-IAMEBBC/ IBSc)

3.12. Effect of streptozotocin (singly) and streptozotocin in combination with nicotinamide to developed T2DM mice: In this study, the effect of streptozotocin (singly) and streptozotocin in combination with nicotinamide was compare. The experimental out come would refer that nicotinamide offers a partial protection against $\beta$-cytoxic effect of streptozotocin. Masiello et al. [20] claimed that pretreatment of nicotinamide offered $\sim 40 \%$ preservation of pancreatic insulin stores and developed T2DM in adult mice. Therefore, streptozotocin-nicotinamide model has chosen for this study to evaluate oral hypoglycemic effect of Abroma Augusta (AA) green fruits and flower alcoholic extract.

3.13. Induction of $T 2$ Diabetes Mellitus and experimental design: T2Diabetes Mellitus was induced in overnight fasted mice by a single intra-peritoneal injection of streptozotocin $(65 \mathrm{mg} / \mathrm{kg})$ in citrate buffer ( $\mathrm{pH} 4.5), 15 \mathrm{~min}$ later the administration of nicotinamide (110 mg/kg,). After 1 week, animals exhibiting fasting glucose levels between $140-200 \mathrm{mg} / \mathrm{dl}$ screened as type2 diabetic (T2D) mice ${ }^{\text {[20] }}$ and used for the anti-diabetic assay. The control and effect of test drug (Abroma Augusta L. green fruits and flower extract.) on fasting blood glucose level also investigated.

\section{Animals divided into 7 groups of 4mice each as follows:}

Gr I: Normal mice given double distilled water ( $2 \mathrm{ml} / \mathrm{kg}$, ) daily for 4 weeks;

Gr II: T2D control mice given distilled water ( $2 \mathrm{ml} / \mathrm{kg}$,) daily for 4 weeks;

Gr IIIa: T2D mice given AA (250 mg/kg, green fruit EtOH \& MeOH extract) daily for 4 weeks;

Gr.IIIb: T2D mice given AA (450 mg/kg,green fruits EtOH \& MeOH extract) daily for 4 weeks;

Gr IVa: T2D diabetic mice given AA (250 mg/kg, flower EtOH \& MeOH extract) daily for 4 weeks;

Gr IVb: T2D diabetic mice given AA (450 mg/kg, flower EtOH \& MeOH extract) daily for 4 weeks;

Gr V: T2D mice given standard drug glibenclamide $\left(1 \mathrm{mg} / \mathrm{kg}\right.$, ${ }^{[21]}$ daily for 4 weeks.

3.14. Oral Glucose Tolerance Test (OGTT): Overnight fasted male Swiss Albino mice divided into 7 groups of 4 mice each. OGTT performed by treating the animals with glucose $(1.5 \mathrm{~g} / \mathrm{kg} \text {, })^{\text {[22]. Just after }}$ glucose feeding, four groups (IIIa, IIIb, IVa and IVb) of mice fed with AA $(250,450 \mathrm{mg} / \mathrm{kg}$, ethanol \& methanol fruits extracts and 250, $450 \mathrm{mg} / \mathrm{kg}$, Ethanol \& Methanol flower extract respectively). A group of animals treated with double distilled water $(2 \mathrm{ml} / \mathrm{kg}$,) and kept as control. Blood glucose levels measured at $0 \mathrm{~min}$ and $120 \mathrm{~min}$ after glucose treatment with the help of single touch glucometer (Abbott Diabetes Care Inc, Alameda, USA).

\section{RESULT AND DISCUSSION}

Medicinal plants and herbal plants have assumed massive importance in present days due to the tremendous developments in the field of allopathic medicines during 20th century. Herbal plants play important role in healthcare system of a large number of world's population, plants all over the world being use traditionally in the prevention and treatment of many diseases. The various phytochemical compounds detected to have beneficial importance in medicinal sciences. In these studies, preliminary phytochemical screening of the green fruits and flowers extract of Abroma augustam Linn done to ascertain the presence or absence of bioactive components. Qualitative tests confirmed the presence of Flavonoids, Steroids, Alkaloids, Carbohydrates, and Glycosides and reducing sugars whereas, Saponins 
and Triterpenoids were absent [Table-1]. Abroma augustam contains several kinds of glycosides, flavonoids, gallic acid and phenolic compounds. Many researchers have evaluated that these phytochemical substances have the major impact on diabetes.

Table-1: Phytochemical screening of the green fruits and flowers of Abroma Augustam Linn. plant extract.(+) sign means the presence of chemical active groups and (-) sign means the absent of chemical groups in the Ethanolic and Methanolic extract of green fruits and flowers of Abroma Augusta Linn.

\begin{tabular}{|l|l|lr|lc|}
\hline $\begin{array}{l}\text { SL. } \\
\text { No }\end{array}$ & Bioactive Compound & \multicolumn{2}{|c|}{ Green Fruits extract } & \multicolumn{2}{|c|}{ Mature Flower extract } \\
Ethanol & Methanol & Ethanol & Methanol \\
\hline 1 & Alkaloids & + & ++ & + & + \\
\hline 2 & Steroids & + & + & + & - \\
\hline 3 & Flavonoids & +++ & ++ & + & ++ \\
\hline 4 & Reducing sugars & ++ & + & ++ & ++ \\
\hline 5 & Triterpenoids & - & - & - & - \\
\hline 6 & Carbohydrate & ++ & ++ & ++ & + \\
\hline 7 & Glycosides & +++ & ++ & ++ & ++ \\
\hline 8 & Saponins & -- & - & -- & - \\
\hline 9. & Tannins & + & ++ & ++ & + \\
\hline
\end{tabular}

The total phenolic and flavonoids content of the different solvent extracts of Abroma augustam fruits and flowers standardized for their content of phenolic and flavonoid compounds [Table-2]. Phenolic compounds have redox potentials and can donate hydrogen atoms to the free radicals, so they can act as antioxidant compounds [23]. Based on data in Table 2, the ethanol A.augusta fruits extract fraction had a greater total phenolic content than the methanol extract fruits, ethanol extract flower and methanol extract of flowers fraction. The total phenolic content values of ethanol fruits extract fraction, methanol extract fruits, ethanol extract flower and methanol extract of flowers fraction were 165.16 \pm 1.65 , $112.23 \pm 1.65 ; 66.28 \pm 1.7$; and $65.16 \pm 1.65$; (mg of GAE / gm of dry sample), respectively. The high content of phenols in a sample will affect the strength of antioxidant activity in the sample. The high and low capability of an antioxidant is influenced by high and low phenolic contents in the sample $\mathrm{e}^{[24]}$.

Table-2: Total phenolics and flavonides content of 4 four different extract of A. augustum

\begin{tabular}{|l|l|l|l|l|l|l|}
\hline $\begin{array}{l}\text { Name } \\
\text { of } \\
\text { extracts }\end{array}$ & \multicolumn{2}{|l|}{ Total Phenolic content } & \multicolumn{3}{|c|}{ Total flavonoids contents } \\
\hline & \multicolumn{2}{|c|}{ mg of GAE/gm of dry extract } & \multicolumn{2}{|c|}{ mg of QUE/gm of dry extract } \\
\hline & $\begin{array}{l}\text { Ethanol } \\
\text { extract }\end{array}$ & $\begin{array}{l}\text { Methanol } \\
\text { extract }\end{array}$ & Mean \pm SD & $\begin{array}{l}\text { Ethanol } \\
\text { extract }\end{array}$ & $\begin{array}{l}\text { Methanol } \\
\text { extract }\end{array}$ & Mean \pm SD \\
\hline $\begin{array}{l}\text { Green } \\
\text { fruits }\end{array}$ & $165.17 \pm 1.65$ & $112.23 \pm 1.65$ & $138.7 \pm 1.65$ & $54.23 \pm 2.03$ & $65.17 \pm 1.95$ & $59.7 \pm 1.99$ \\
\hline Flower & $66.27 \pm 1.70$ & $65.16 \pm 1.65$ & $65.71 \pm 1.65$ & $46.78 \pm 1.90$ & $45.17 \pm 2.01$ & $45.98 \pm 1.96$ \\
\hline
\end{tabular}

Table 2 shows the total flavonoid content of the extracts of A. augusta green fruits and flowers. The methanolic fruits extract contained the highest amount of flavonoid compounds to the ethanol extract fruits, ethanol extract flower and methanol extract of flowers with a value of $65.17 \pm 1.95,54.23 \pm 2.05$; $46.78 \pm 1.9 ; 45.16 \pm 2.01$ ( $\mathrm{mg}$ of QUE / gm of dry extract) respectively. Flavonoid is needed by the human body to maintain good health ${ }^{[25]}$. 
The effect of test drug on fasting blood glucose level investigated. In our study, an acceptable model of T2DM ${ }^{[19]}$ has been used to screen antidiabetic effect of $A$. augusta green fruits and flower extract from methanol and ethanol at different doses.

4.1. Effect on OGTT: Streptozotocin-nicotinamide induced T2DM model experimental mice chosen for this study. The OGTT study revealed that, oral administration of ethanolic extract of green fruits $A$ augusta $(250,450 \mathrm{mg} / \mathrm{kg})$ significantly $(\mathrm{p}<0.05-0.01)$ reduced blood glucose concentrations between 30-60 min after glucose $(1.5 \mathrm{mg} / \mathrm{kg})$ load compared to methanolic extract of A augusta green fruits (Figure-3). Methanolic and ethanolic extract of A. augustam mature flower shows a little antidiabetic's effect. Therefore, our present investigation performed to evaluate and compare the protective effect of alcoholic extract of A. augustam green fruits and flowers extract only on T2DM.

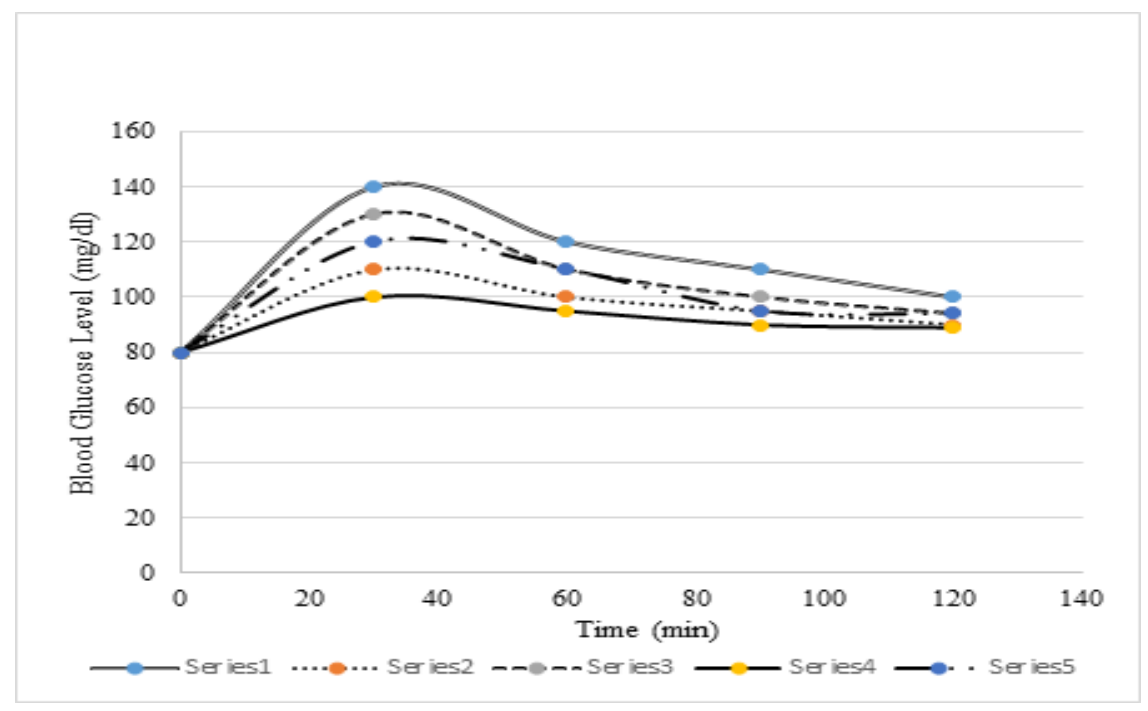

Fig.3: Effect of AA EtOH and $\mathrm{MeOH}$ extract of fruits on oral glucose tolerance test on T2DM mice

4.2. Effect on fasting blood glucose level: Single touch glucometer (Abbott Diabetes Care Inc, Alameda, USA) utilized to estimate fasting blood glucose level on $0,1,3,7,14,21$ and 28days. A significantly $(\mathrm{p}<0.01)$ high fasting blood glucose level $(170-190 \mathrm{mg} / \mathrm{dl})$ was observed in T2DM mice. Maintenance of blood glucose level within normal range is a primary approach during T2DM treatment. Ethanolic green fruit extract $A$ augustam $(250$ and $450 \mathrm{mg} / \mathrm{kg}$ ) treatment could significantly reduce fasting blood glucose level in T2D mice with maximum reduction of $\sim 24.7 \%(\mathrm{p}<0.01)$ and $~ 37.0 \%$ ( $\mathrm{p}<0.01)$ on the day 28 , respectively. Whereas methanolic extract of fruits $(250$ and $450 \mathrm{mg} / \mathrm{kg}$ ) also has a little antidiabetics effect ( 16\% \& 18\%) [Table-3, Fig-4]. However, ethanolic and methanolic extract of A. augustam flowers $(250$ and $450 \mathrm{mg} / \mathrm{kg}$ ) treatment finding results were not satisfactory [Table-4, Fig-5]. The standard drug glibenclamide $(1 \mathrm{mg} / \mathrm{kg})$ exhibited maximum reduction of $42.52 \%$ ( $p<0.01)$ on 28days [Fig-4, 5] ${ }^{[26]}$. Finding results indicate that green fruits of ethanolic and methanolic extract induce T2DM significantly compared to flower extract bioactive materials .The methanolic extract of the leaves of Devil's cotton are used in the treatment of alloxan-induced diabetic rats at a dose of $300 \mathrm{mg} / \mathrm{kg}$ body weight when administered for seven days [27, 28, 29], which supported our findings. In this investigation, we found a rich source of phenolic and flavonoid compounds in the green fruits extract of A. augustam can used to treat various ailments compared to flower extract. The results provide a justification for future clinical trials of $A$. augustam green fruits extract for the development of oral hypoglycemic agent employing natural resources. The preliminary phytochemical screening tests may be beneficial in the detection of the bioactive components and may lead to the drug formulation and great importance in the field of drug research or drug discovery field. 
Table 3: Effect of A. augustum (AA ) EtOH and $\mathrm{MeOH}$ extract of green fruits on fasting blood glucose level of T2D mice Groups. Fasting blood glucose level ( $\left.\mathrm{mg} \mathrm{dl}^{-1}\right)$.

\begin{tabular}{|l|l|l|l|l|l|l|l|}
\hline & 0 day & 1 days & 3 days & 7 days & 14 days & 21 days & 28 days \\
\hline Gr. I & $86.2 \pm 3.4$ & $85.8 \pm 2.74$ & $86.4 \pm 2.94$ & $86.1 \pm 3.70$ & $84.9 \pm 3.04$ & $84.8 \pm 2.74$ & $84.3 \pm 3.0$ \\
\hline Gr. II & $174.9 \pm 3.8$ & $168.9 \pm 4.2$ & $169.9 \pm 4.83$ & $168.9 \pm 3.7$ & $170.1 \pm 4.8$ & $169.9 \pm 2.93$ & $168.9 \pm 3.83$ \\
\hline Gr.IIIa & $173.8 \pm 4.75$ & $168.8 \pm 2.8$ & $164.9 \pm 3.73$ & $153.8 \pm 4.3$ & $140.0 \pm 3.93$ & $135.0 \pm 3.89$ & $130.9 \pm 4.83$ \\
Gr.IIIb & $174.5 \pm 6.86$ & $165.6 \pm 4.3$ & $163.9 \pm 2.89$ & $150.7 \pm 3.7$ & $136.8 \pm 4.83$ & $120.6 \pm 2.93$ & $109.9 \pm 2.73$ \\
& & & & & & & \\
\hline Gr.IVa & $173.8 \pm 4.75$ & $165.8 \pm 2.8$ & $162.1 \pm 3.73$ & $150.8 \pm 4.3$ & $150.7 \pm 3.93$ & $149.7 \pm 3.89$ & $145.9 \pm 4.83$ \\
Gr.IVb & $174.5 \pm 6.86$ & $166.6 \pm 4.3$ & $160.9 \pm 2.89$ & $148.7 \pm 3.7$ & $146.8 \pm 4.83$ & $143.6 \pm 2.93$ & $142.9 \pm 2.73$ \\
& & & & & & & \\
\hline Gr. V & $173.9 \pm 3.88$ & $155.8 \pm 3.83$ & $138.5 \pm 4.83$ & $122.4 \pm 2.89$ & $110.6 \pm 3.73$ & $90.7 \pm 3.78$ & $88.1 \pm 4.83$ \\
\hline
\end{tabular}

** Data were expressed as mean \pm SE $(n=6)$. \# p < 0.01 compared with normal control group. *p < 0.05 compared with diabetic control group. $* * \mathrm{p}<0.01$ compared with diabetic control group. Gr I: Normal; Gr II: T2D control, Gr IIIa: T2D + EtOH extract of fruits AA (250 mg/kg); Gr IIIb: T2D +EtOH extract of fruits AA $(450 \mathrm{mg} / \mathrm{kg})$; Gr IVa: T2D + MeOH extract of fruits AA (250 mg/kg); Gr IVb: T2D + MeOH extract of fruits AA (450 mg/kg); Gr V: T2D + glibenclamide $(1 \mathrm{mg} / \mathrm{kg})$.

Table 4: Effect of EtOH and $\mathrm{MeOH}$ extract of A. augustum(AA ) flowers on fasting blood glucose level of T2D mice Groups. Fasting blood glucose level $\left(\mathrm{mg} \mathrm{dl}^{-1}\right)$.

\begin{tabular}{|l|l|l|l|l|l|l|l|}
\hline & 0 day & 1 days & 3 days & 7 days & 14 days & 21 days & 28 days \\
\hline Gr. I & $86.2 \pm 3.4$ & $85.8 \pm 2.74$ & $86.4 \pm 2.94$ & $86.1 \pm 3.70$ & $84.9 \pm 3.04$ & $84.8 \pm 2.74$ & $84.3 \pm 3.0$ \\
\hline Gr. II & $174.9 \pm 3.8$ & $168.9 \pm 4.2$ & $169.0 \pm 4.83$ & $168.9 \pm 3.7$ & $170.1 \pm 4.8$ & $169.9 \pm 2.93$ & $168.9 \pm 3.83$ \\
\hline Gr.IIIa & $172.9 \pm 2.6$ & $171.8 \pm 1.65$ & $170.2 \pm 3.61$ & $168.9 \pm 2.67$ & $167.2 \pm 1.65$ & $162.9 \pm 2.69$ & $158.1 \pm 3.6$ \\
Gr.IIb & $172.9 \pm 2.8$ & $170.9 \pm 2.75$ & $168.9 \pm 1.68$ & $162.9 \pm 3.2$ & $165.6 \pm 2.9$ & $158.7 \pm 3.6$ & $155.9 \pm 2.5$ \\
\hline Gr.IVa & $173.5 \pm 5.86$ & $170.6 \pm 4.3$ & $167.9 \pm 2.89$ & $167.7 \pm 3.7$ & $166.8 \pm 4.83$ & $163.6 \pm 2.93$ & $158.9 \pm 2.73$ \\
Gr.IVb & $173.9 \pm 2.8$ & $171.9 \pm 2.75$ & $168.9 \pm 1.68$ & $164.9 \pm 3.2$ & $165.6 \pm 2.9$ & $158.7 \pm 3.6$ & $154.9 \pm 2.5$ \\
\hline Gr. V & $173.9 \pm 3.88$ & $155.8 \pm 3.83$ & $138.5 \pm 4.83$ & $122.4 \pm 2.89$ & $110.6 \pm 3.73$ & $90.7 \pm 3.78$ & $88.1 \pm 4.83$ \\
\hline
\end{tabular}

** Data were expressed as mean $\pm \mathrm{SE}(\mathrm{n}=6)$. Gr I: Normal; Gr II: T2D control, Gr IIIa: T2D + EtOH extract of flower AA (250 mg/kg); Gr IIIb: T2D +EtOH extract of flowers AA (450 mg/kg); Gr IVa: T2D + MeOH extract of flower AA (250 mg/kg); Gr IVb: T2D + MeOH extract of flowers AA (450 mg/kg); Gr V: T2D + glibenclamide $(1 \mathrm{mg} / \mathrm{kg})$.

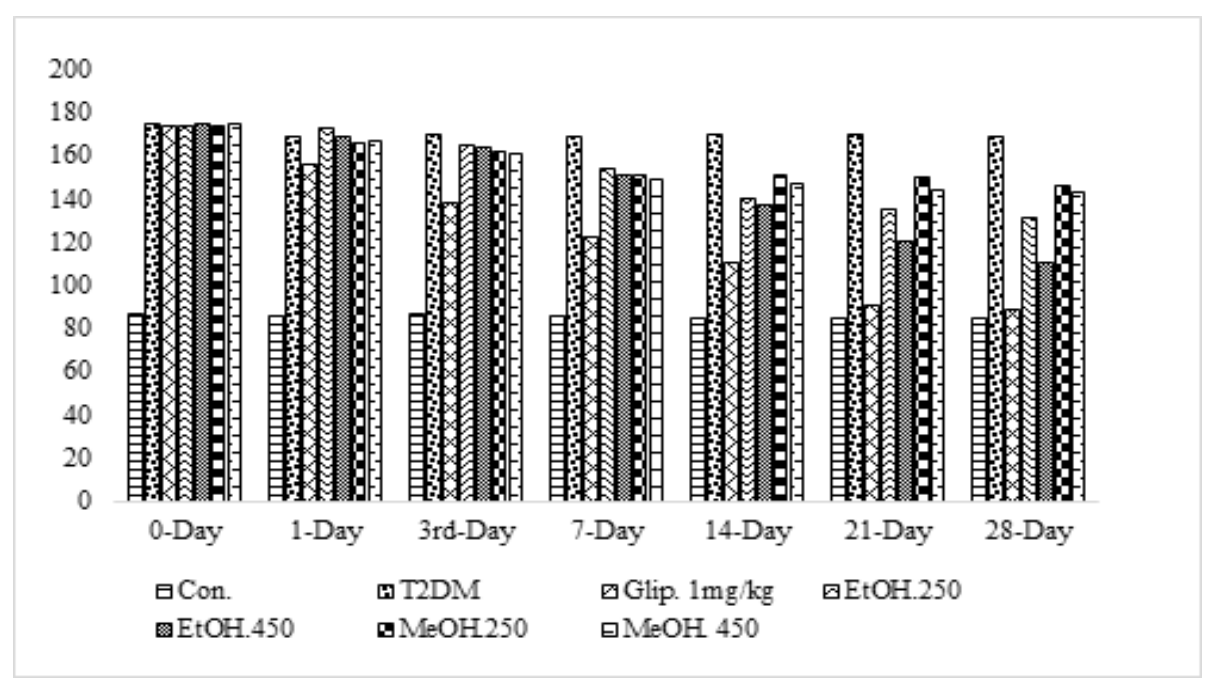

Fig.4: Effect of EtOH and $\mathrm{MeOH}$ extract of A.augustum fruits on T2DM mice 


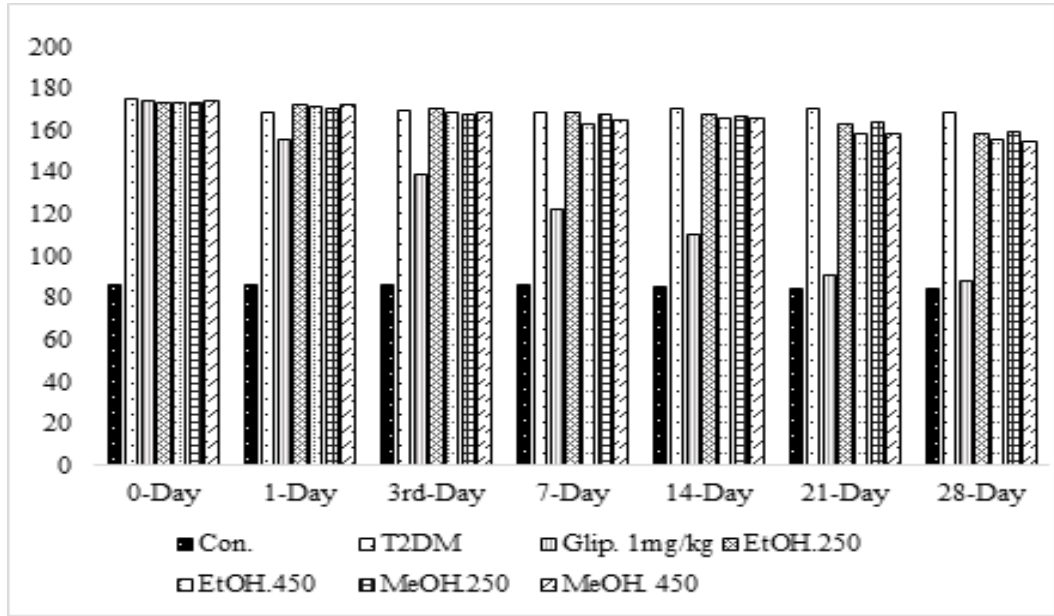

Fig.5: Effect of EtOH and $\mathrm{MeOH}$ extract of A.augstum flowers on T2D mice

\section{CONCLUSION}

Herbal medicine is the oldest form of healthcare known to humankind. It is an integral part of the development of modern evaluation. One of the herbal gift is Abroma augustam (Ulatkambal) contains several pharmacological activities. From phytochemical analysis it was found that various phytochemical constituents mainly glycoside, flavonoids, gallic acid and phenolic compounds are present in this plant green fruits and mature flowers. Many researchers have evaluated that these phytochemical substances have the major impact on diabetes. We can conclude with that the green fruits of A. augusta Linn might have anti-diabetics properties as observed in Streptozotocin-nicotinamide induced T2DM model experimental rats test. Based on the result of this present study, it can concluded that the crude plant green fruits extracts of A. augustum possesses remarkable diabetic's potential compared to flower extract. The results provide a justification for future clinical trials of A. augusta green fruits extract (chemically defined) for the development of oral hypoglycemic agent employing natural resources. Therefore, extensive research should be necessary in the area of isolation and characterization of unknown bioactive compounds from this medicinally renowned plant species.

\section{ACKNOWLEDGMENTS}

Funding: This work supported by partial Grants Ref.No. 1389/5/52/RU/Science-17/18-19, 602/5/52/RU/Science-17/18-19 from Faculty of Science, Rajshahi University, Rajshahi, Bangladesh.

Conflicts of Interest: The authors declare no conflict of interest.

\section{REFERENCES}

1. M.A.M. Bhuiya, B.Talukdar, M. Ajrin, S. Akter, and R. Sen,. In vitro thrombolytic and antioxidant activity study of Abroma augusta (Ulatkambal). The Experiment. 2013,(14), 888-893.

2. R. Small and P. M. Catling, Canadian Medicinal Plant Biodiversity Priority Issues, 2003.

3. A. Nostro, . V. Gemano,A. Dangelo, M.A. Marino. Cannatelli, Extraction methods and bioautography for evaluation of medicinal plants antimicrobial activity", Lett Appl microbial, 2000, 30(5): 379-384. 
4. T.R. Doctor, and J.F. Manuel, Phytochemical Screening of Selected Indigenous Medicinal Plants of Tublay, Benguet Province, Cordillera Administrative Region, Philippines. International Journal of Scientific and Research Publications, 2014; 4(4).

5. S.A. Bukhari, W.A. Shamshari, M. Rahman, M. Zia-Ul-Haq, HZE. Jaafar . Computer aided screening of secreted frizzled-related protein 4 (SFRP4): a potential control for diabetes mellitus. Molecules. 2014,(19):10129-36.

6. E. Fernández-Millán, S. Ramos, C. Alvarez, L. Bravo, L. Goya. Microbial phenolic metabolites improve glucose-stimulated insulin secretion and protect pancreatic beta cells against tert-butyl hydroperoxide-induced toxicity via ERKs and PKC pathways. Food Chem Toxicol. 2014,(66):245-53.

7. A. Ramachandram, C. Snehalatha, A.S. Shetty, A. Nanditha . Trends in prevalence of diabetes in Asian countries. World J Diabetes, 2012; (3): 110-117.

8. Anonymus "The wealth of India" dictionary of Indian raw materials and industrial products. The council of scientific and industrial research. (NISCAIR press publisher; New Delhi 2006) $: 222$.

9. K.R. Kritikar and B.D. Basu . text book of "Indian medicinal plants", vol.1 IInd ed. (Surendra Nath Basu publishers, Bahadur Ganj, Allahabad) 1999. :379.

10. Agro techniques of selected medicinal plants", vol. I, National medicinal plants board. Department of AYUSH, ministry of health and family welfare, (TERI press The Energy and resources Institute. New Delhi), 2008 (1).

11. R. Bisht, S. Bhattacharya, and Y.A. Jaliwala. Evaluating the use of root extract of Abroma augusta as alpha glucosidase inhibitor for type-II diabetes. Annals Plant Sci. 2014. (3): 686691.

12. S.R.E. Reddy, P.K. Sharma, P. Raj. Effect of Abroma augusta mother tincture in type 2 diabetes mellitus by assigning blood glucose levels - a clinical study. Inter. J. Recent Sci. Res., 2018. (9): 24687-24691.

13. J. Bhandari, B. Muhammad, P. Thapa, and B. G. Shrestha, "Study of phytochemical, antimicrobial, anti-oxidant, and anti-cancer properties of Allium wallichii," BMC Complementary Alternative Medicine., , 2017, vol. 17, no. 1, p. 102.

14. A. Sofowora, "Screening plants for bioactive agents," Medicinal Plants Traditional Medicine in Africa, 1993, vol. 2, pp. 134-156,

15. S. Mc Donald, PD. Prenzler ,M. Autolovich ,K. Robards . Phenolic content and antioxidant activity of olive extracts. Food Chem., 2001, (73): 73- 84.

16. R.M.Y. Morsi ,N.R.E.L. Tahan, A.M.A. El-Hadad. Effect of aqueous extract Mangifera Indica leaves, as functional foods. J. Appl. Sci. Res., 2010. (6): 712-721

17. C.Chang, M. Yang, H. Wen, J. Chern, Estimation of total flavonoid content in propolis by two complementary colorimetric methods. J. Food Drug Anal.,2002, 10: 178-182.

18. K. Ghasemi, Y.D. Ghasemi , M.A. Ebrahimzadeh ). Antioxidant activity, phenol and flavonoid contents of 13 citrus species peels and tissues. Pak. J. Pharm. Sci., 2009,(22): 277-281. 
19. M. Kaneria , Y. Baravalia , Y. Vaghasiya , S. Chanda . Determination of antibacterial and antioxidant potential of some medicinal plants from Saurashtra region, India. Indian J. Pharm. Sci., 2009. (71): 406-412.,.

20. P. Masiello, C. Broca, R. Gross, M. Roye, M. Manteghetti. Experimental NIDDM: development of a new model in adult rats administered streptozotocin and nicotinamide. Diabetes., 1998; (47):224-229

21. S. Dewanjee, A.K. Das , R. Sahu , M. Gangopadhyay . Antidiabetic activity of Diospyros peregrina fruit: effect on hyperglycemia, hyperlipidemia and augmented oxidative stress in experimental type 2 diabetes. Food Chem Toxicol. 2009; (47):2679-2685.

22. A. Kar, B.K. Choudhary, N.G. Bandyopadhyay. Preliminary studies on the inorganic constituents of some indigenous hypoglycaemic herbs on oral glucose tolerance test. $J$ Ethnopharmacol., 1999 (64):179-184.

23. M.A.Soobrattee, V.S. Neergheen and A. Luximon-ramma,, Phenolics as potential antioxidant therapeutic agents : Mechanism and actions. Mutation Research,2005, 579(1-2), 200-213.

24. P. Duh, Y.Tu and G. Yen, Antioxidant Activity of Water Extract of Harng Jyur (Chrysanthemum morifolium Ramat). LWT - Food Science and Technology, 1999, 32(5), 269277.

25. P. Shi, W. Du, Y. Wang, X. Teng, X. Chen, and L. Ye, Total phenolic, flavonoid content, and antioxidant activity of bulbs, leaves, and flowers made from Eleutherine bulbosa (Mill.) Urb. Food Science and Nutrition,2019, 7(1), 148-154.

26. S. Dewanjee, A. Maiti, R. Sahu, T.K. Dua , V. Mandal . Effective control of type-2 diabetes through antioxidant defense by edible fruits of Diospyros peregrina. Evi Based Compliment Alter Med. 2011, Article ID 675397: doi:10.1093/ecam/nep080

27. S.B. Mishra, C.V. Rao, S.K. Ojha, S. Alok, and A. Verma,. An analytical review of plants for antidiabetic activity with their phytoconstituents and mechanism of action. Indian $J$. Pharmaceut. Sci. Res. 2010. (1): 29-46.

28. L. Nahar, A.R. Farhana, M. Haque, and D.K.M.S.Islam, Comparative study of antidiabetic effect of Abroma augusta and Syzygium cumini on alloxan induced diabetic rat. Agricul. Biol. J. North Amer., 2010. (1): 1268-1272.

29. D.R. Chhetri, P. Parajuli, and G.C. Subba.. Antidiabetic plants used by Sikkim and Darjeeling Himalayan tribes, India. J. Ethnopharmacol., 2005(99): 199- 202.

\section{* Corresponding Author: R.K.Shaha,}

Department of Biochemistry and Molecular Biology, Rajshahi University, Rajshahi-6205, Bangladesh

Online date of publication: 15.10.2021 